\title{
EVALUATION OF TWIST SPRINGBACK PREDICTION AFTER AN AHSS FORMING PROCESS
}

\author{
Dezelak, M. ; Stepisnik, A. ; Pahole, I. ${ }^{* *} \&$ Ficko, M.* \\ *Emo Orodjarna d. o. o., Bezigrajska 10, SI-3000 Celje, Slovenia \\ ** University of Maribor, Faculty of Mechanical Engineering, Smetanova 17, 2000 Maribor, Slovenia \\ E-Mail: mihael.dezelak@emo-orodjarna.si
}

\begin{abstract}
The springback of a sheet metal part is the change of its shape after removing a forming tool. An accurate prediction of springback is very difficult because sheet metal undergoes a complicated deformation process during the forming process. These are the following types of springback when considering the geometry of the product and the forming regime: angular change, sidewall curl, and twist. The latter is the key issue of this paper. A new definition of twist springback is proposed having been tested on a referenced sheet metal part. An experimental device for twist springback testing has been designed and the effect of blank rolling direction on the twist was investigated for dual-phase (DP) sheet steel. Finite element method (FEM) results of twisting behaviour using AutoForm software for different material models were compared with the experimental and the correlation evaluation was performed.

(Received in October 2013, accepted in December 2013. This paper was with the authors 1 month for 1 revision.)
\end{abstract}

Key Words: Sheet Metal Forming, Twist Springback, FEM, Experiment

\section{INTRODUCTION}

The change of a sheet metal part's shape after the forming process is driven by the release of internal elastic residual stresses after forming tool removal [1]. High strength steel and aluminium alloy sheets are more prone to this geometrical deviation compared to mild steel sheets because of the relatively high level of elastic deformation during the forming process [2]. There are three general types of springback when considering the geometry of the product and the forming regime (Fig. 1): angular change, sidewall curl, and twist. During the deep drawing process sheet metals show a combination of angular changes and sidewall curls which usually occur in the walls of the products, while the effect of torsional springback deviation - twist is visible over the entire area of the product with changeable cross-sections [3].

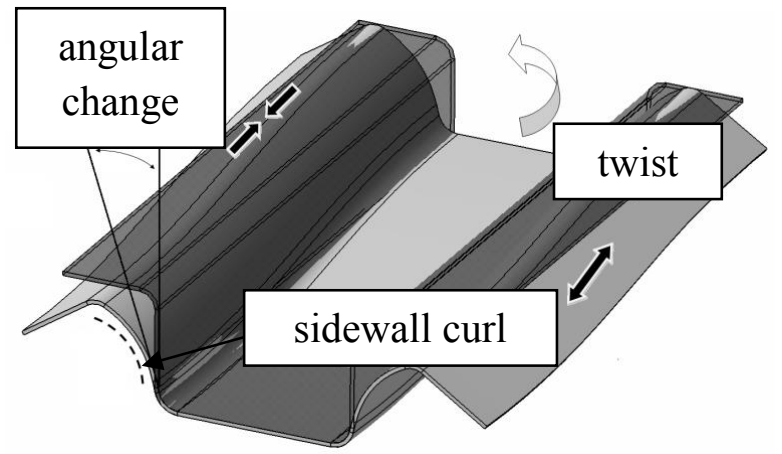

Figure 1: General types of springback.

The springback phenomenon usually causes geometrical unsuitability and unreliability of the sheet metal part after forming and for this reason correction and adaptation is needed of 
physical forming tools. The main goal today is to minimise the number of physical iterations of the forming tool's adaptations in order to achieve geometrical accuracy of the product and sufficient robustness of the production process [4]. A number of researchers during the past twenty years have tried to understand the background of the springback phenomenon and wanted to find ways of overcoming or at least controlling it [5-14]. The introduction of the new Advanced High Strength Steel (AHSS) into the automotive industry has made springback issues even more prominent.

Finite element method (FEM) simulations are today the common tool for verifying the manufacturability of sheet metal parts and their springback predictions. Roll [15] clearly presents the importance of industrial FEM simulations and proffers some suggestions for achieving more accurate forming process evaluations.

Li et al. [16] present twist springback research for reference sheet metal parts made of high-strength steel. The effects of different design and process parameters (cross-section width ratio, corner angle, draw-bead depth and steel grades) were investigated for four advanced high-strength raw materials. Torsion moments were the greatest causers of twist springback appearance. Takamura et al. [17, 18] analysed the $U$ channel twist springback problem, where the draw ratio effect was investigated. They found that shear stress and sidewall curl were two important factors that had an evident influence on twist springback. The value of shear stress increased during the deep drawing process for bigger drawing rations cases because of in-plane deformations of flange and wall areas. Sidewall curl was expressed especially in those drawing parts with higher walls and for this reason such parts also presented good conditions for the twist springback phenomenon.

In paper [19] the effects of anisotropic yield functions and elastic forming tool deformation on twist springback after the sheet metal forming process of high- strength steels were investigated. Comparison was made between the finite element method when forming simulation results and the measurements after physical experimentation. It was found that numerical models that consider elastic deformation of forming tools were able to predict twist springback more accurately compared to common models.

Twist springback measurement has not as yet been commonly defined and for this reason a definition of twist springback is proposed. The continuation presents twist springback testing parts and experimental device. Results are compared between FEM AutoForm [20] simulations for different material models and the experimental measurements of twist springback. A criterion of correlation coefficient was implemented for evaluating and comparing numerical models.

\section{METHODS}

\subsection{Twist Springback}

Springback research is mostly orientated towards angular change and sidewall curl. Twist springback that is actually the consequence of previously-mentioned springback types is more or less disregarded. In addition, twist springback has not as yet been properly defined and its value is integrated within the total springback estimation of a sheet metal part. Twist springback is caused by torsion moments within the cross-section of the part and the logical consequence is the different rotations of two cross-sections along their axes. Torsion moment is induced by unbalanced springback and in plane residual stresses in the wall and flange of the part. Twist springback's appearance is in fact the relationship between unbalanced stresses and part rigidity, according to twist tendency direction. Geometrical parameters have a big influence on twist springback. Sheet metal products with lower thicknesses and rigidities 
show higher twist tendencies. There is also the so-called lever effect - dimensionally bigger parts are more prone to twisting behaviour.

Unbalanced forces, the greatest twist springback causers, usually occur in sheet metal parts with bigger flanges and walls, and in parts with quick cross-sectional profile changes. Parts with unequal flanges or unsymmetrical cutting operations after drawing operation are affected by unbalanced forces because of non-uniform deformation gradients. Torsion moments can even appear in symmetrical parts during real forming process conditions because of problems of accurate sheet metal positioning, non-uniform lubrication, inaccurate polishing, unequal blank holding, damaged or bad designed draw beads, etc. All these mentioned conditions cause unequal material flow into the die cavity during the deep drawing process and are the seeds of twist springback phenomena [3].

Before the starting sensitive analysis of twist springback, it is necessary to define what twist actually is and how to measure it. This paper proposes a cross-sectional measurement of the sheet metal part according to the rotation across the reference curve (artificial centre curve). The whole section or just part of it is approximated into a linear function - line $(1,2)$. The rotation of this line is then defined as twist springback, expressed in $\Delta \theta$ angle $(3,4,5)$ (Fig. 2).

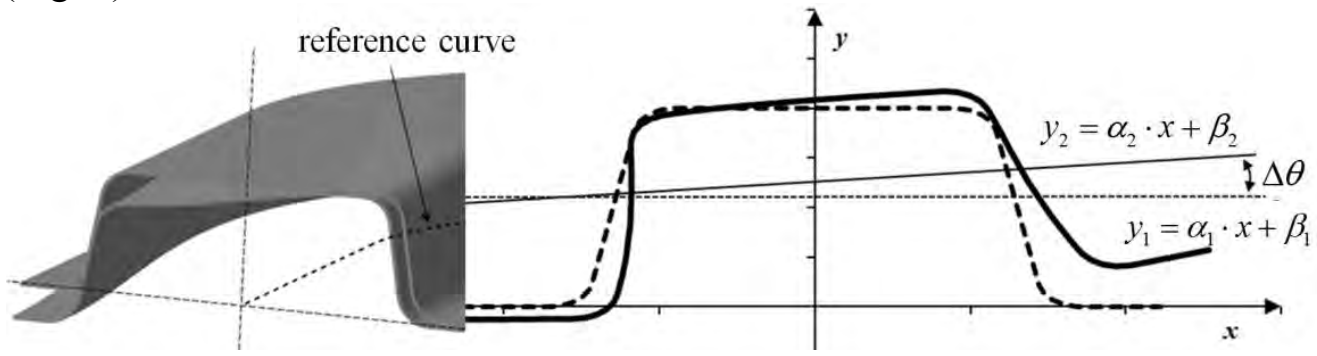

Figure 2: Twist springback definition.

Starting section profile (before springback):

$$
y_{1}=\alpha_{1} \cdot x+\beta_{1}
$$

Final section profile (after springback):

$$
y_{2}=\alpha_{2} \cdot x+\beta_{2}
$$

Section rotation - twist springback is defined as:

$$
\begin{gathered}
\alpha=\operatorname{tg} \theta \Rightarrow \theta=\operatorname{arctg} \alpha \\
\Delta \theta=\theta_{2}-\theta_{1}=\operatorname{arctg} \alpha_{2}-\operatorname{arctg} \alpha_{1}
\end{gathered}
$$

If the section profile is symmetrical, then $\alpha_{1}=0$ and:

$$
\Delta \theta=\operatorname{arctg} \alpha_{2}
$$

Linear functions before and after springback are defined using the least square method [21]. Measurements and FEM simulation provide a data set of $n$ points $-x$ and $y$ coordinate of each point on the section profile. There are $n$ number of data pairs $\left(x_{i}, y_{i}\right), i=1, \ldots n$, where $x_{i}$ is an independent variable and $y_{i}$ is the measured value. The goal of the least square method is to find those parameters $\alpha$ and $\beta$ of the linear function that best fit all the pairs of the data. Its optimal values are defined when the sum $S(6,8)$ of squared residuals $r(7)$ has a minimum value. A residual is actually the difference between the measured value $y_{i}$ and the predicted value with the linear function model (Fig. 3 left):

$$
S=\sum_{i=1}^{n} r_{i}^{2}
$$




$$
\begin{gathered}
r_{i}=y_{i}-f\left(x_{i}, \alpha, \beta\right) \\
S(\alpha, \beta)=\sum_{i=1}^{n}\left(y_{i}-\left(\alpha x_{i}+\beta\right)\right)^{2}
\end{gathered}
$$
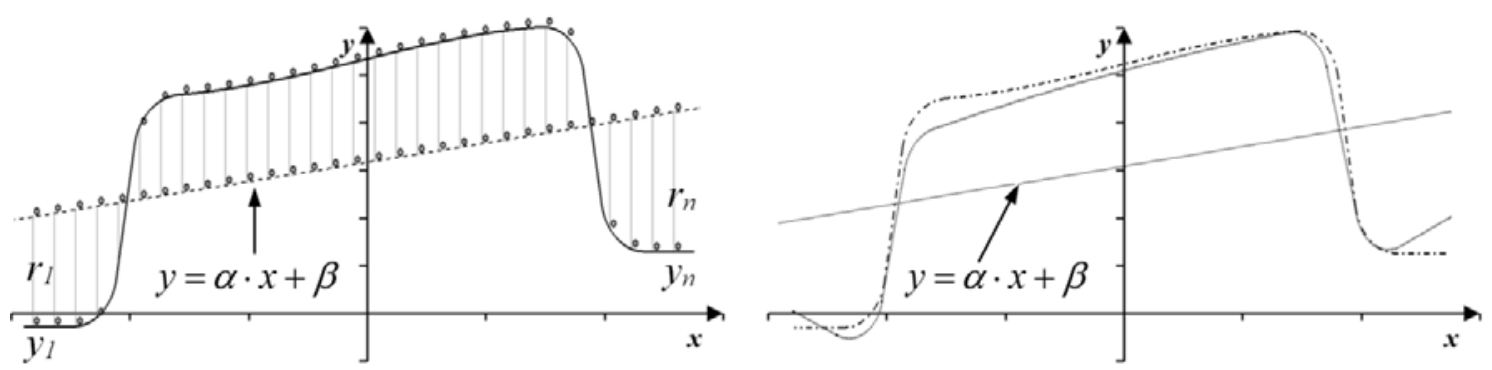

Figure 3: Section profile approximation (left) and examples of different sectional profiles but the same value of twist springback (right).

Other types of springback (angular change and sidewall curve) can have influences on the values of the proposed twist springback definition. This leads to the question as to which part of the sectional profile to take for twist springback definition, the whole profile or just the middle part (part bottom). In other words, different profile shapes because of different angular changes and sidewall curls can have the same values for twist springback (Fig. 3 right).

\subsection{Testing part definition and experimental procedure}

A characteristic sheet metal part was designed for twist springback investigation (Fig. 4). It is relatively simple and similar enough to more complicated sheet metal parts from the automotive industry. It's shape is a wrapped U-channel with a changeable cross-section. Twist springback is to be expected even more because of asymmetry.

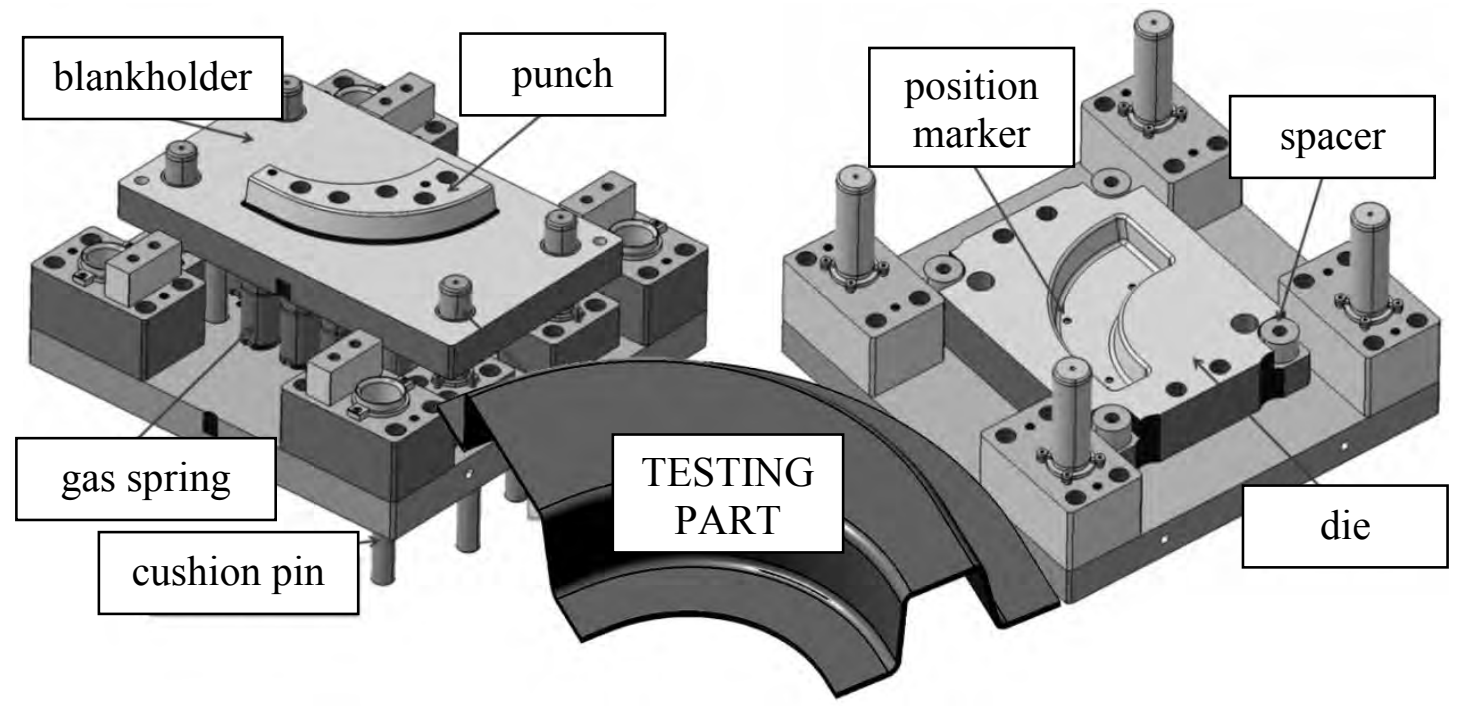

Figure 4: Experimental device (below - left part and upper - right part) and testing part.

This experimental device (Fig. 4 and Fig. 5) was designed as a sheet metal-forming tool for the deep drawing process with all the basic elements that real industrial tools have. Two sources are used for blank holding: gas springs and press air cushion. The blank holding force can be varied with the changing pressures of gas in both holding sources. In order to ensure accurate and robust origins of all parts' measurements, positional markers were used to set drilled holes positions for parts' orientations. 

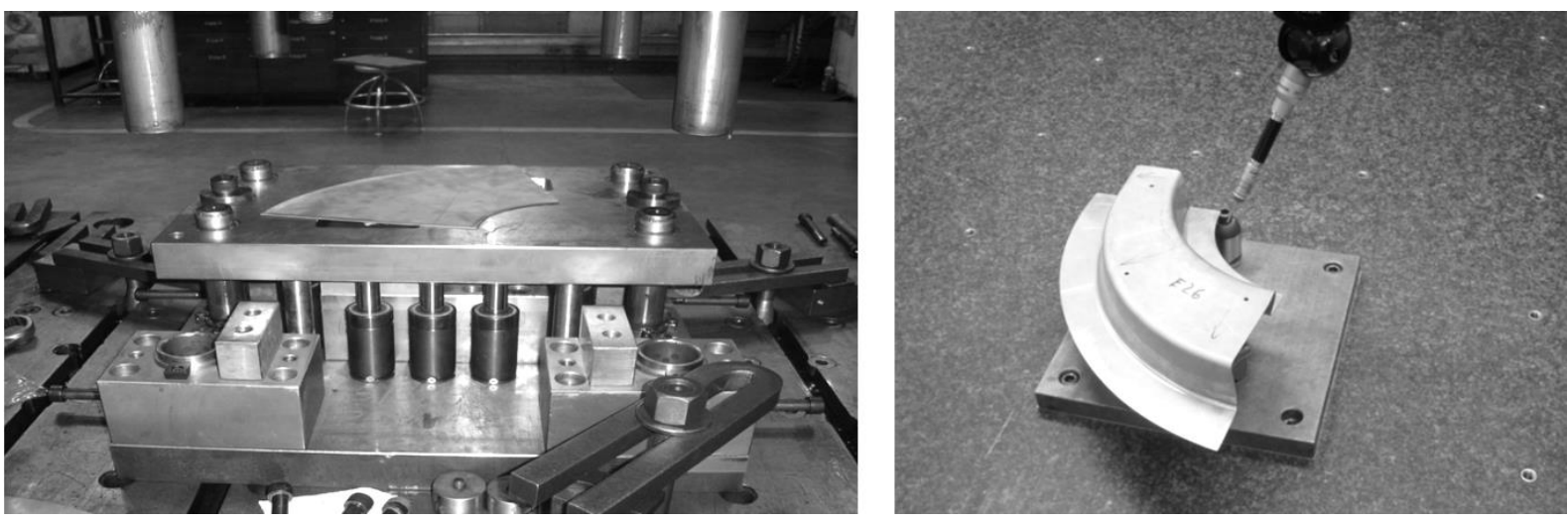

Figure 5: Experimental device during the press and measurement process on a coordinate measuring machine.

Four different orientations (Fig. 6 left) of the blanks were tested to analyse the effect of the rolling direction on the twist springback phenomenon and for each direction three try-outs were performed to test repeatability. Three sections of the reference part were analysed precisely in order to evaluate twist springback. The same origin was applied for the measurements of experimental results and also for FEM simulation, thus enabling adequate twist springback results' comparisons (Fig. 6 right).

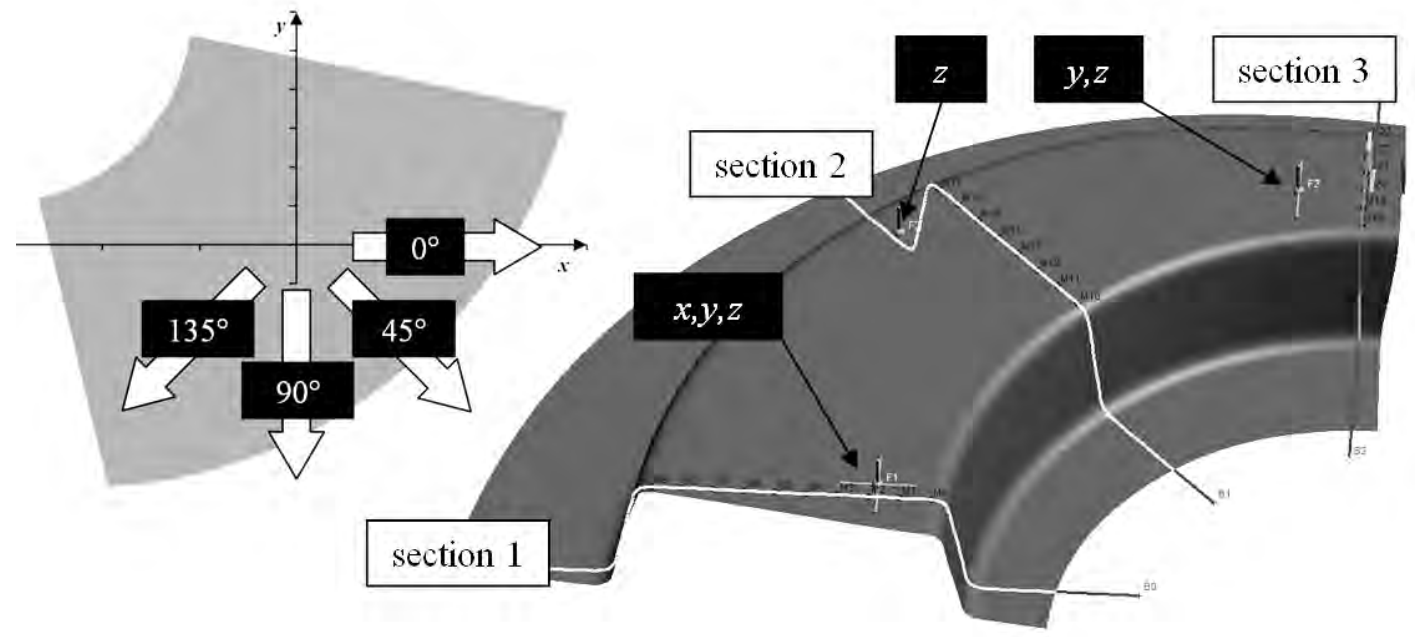

Figure 6: Tested orientations of blank rolling direction (left) and sections for twist springback evaluation with reference points for part adjustment (right).

\subsection{Testing material properties}

It is well-known that introducing advanced high strength materials into the automotive industry has increased the springback problem. One of the more frequently used materials is dual phase (DP) sheet steel. DP consists of a matrix containing a hard martensitic second phase in the form of islands. It's microstructure exhibits higher initial work hardening rate and higher ultimate tensile strength [3]. Sheet steel HCT780 XD with a thickness of $1.2 \mathrm{~mm}$ was used for the twist springback testing. Standard experiments of sheet metal formability properties were performed for three angles $\left(0^{\circ}, 45^{\circ}\right.$ and $\left.90^{\circ}\right)$ according to the sheet metal rolling direction. Five measurements were made for each rolling direction and Table I presents the average values of the material properties' measurements. The material models for FEM simulations in AutoForm were derived at on the basis of the experimental data. 
Table I: Sheet metal material properties - HCT 780XD.

\begin{tabular}{|l|l|c|c|c|}
\cline { 3 - 4 } \multicolumn{2}{l|}{} & $\mathbf{0}^{\circ}$ & $\mathbf{4 5}^{\circ}$ & $\mathbf{9 0}^{\circ}$ \\
\hline $\boldsymbol{n}[/]$ & work hardening exponent & 0.151 & 0.153 & 0.150 \\
\hline $\boldsymbol{C}[\mathrm{MPa}]$ & hypothetical stress for strain 1 & 1333.7 & 1302.3 & 1348.6 \\
\hline $\boldsymbol{R}_{\boldsymbol{m}}[\mathrm{MPa}]$ & tensile strength & 849.9 & 829.0 & 861.8 \\
\hline $\boldsymbol{R}_{\boldsymbol{p} \boldsymbol{0 . 2}[\mathrm{MPa}]}$ & yield stress & 554.8 & 580.5 & 571.6 \\
\hline $\boldsymbol{A}_{\boldsymbol{g}}[\%]$ & specimen deformation at $R_{m}$ & 11.56 & 12.58 & 11.50 \\
\hline $\boldsymbol{A}_{\boldsymbol{8} \boldsymbol{0}}[\%]$ & total specimen deformation & 16.16 & 17.32 & 16.17 \\
\hline $\boldsymbol{r}$ & coefficient of anisotropy & 0.570 & 0.912 & 0.710 \\
\hline
\end{tabular}

\subsection{FEM simulation}

The FEM springback prediction results take their source from the quality of the performed forming simulation. The number of numerical parameters within each simulation step can have a significant impact on the final forecast changes in geometry after the withdrawal of the forming forces, and it was for this reason that the proposed numerical parameters were taken from the literature [5]. The AutoForm software was used for the modelling of the abovementioned experiment. AutoForm Incremental software specialises in the simulation and validation of the complete stamping process [20]. Today it is actually a common tool for sheet metal-forming modelling and springback prediction within industry. The decision to use it for our research work was reasonable for that reason.

The surfaces of the tools are usually considered as rigid bodies. Blankholder as a "cushion pins model" [20] was assumed because of the relatively high values of the forming forces. It's goal is a realistic presentation of binder pressure distribution because of binder deformations.

Elastic plastic shell elements were used with the Gauss thickness integration rule and with eleven integration points through the thickness for sheet metal modelling. The material parameters were taken from the experimental report and modelled with a material generator of the used software. Three different laws were tested for yielding behaviour (Hill [22], Barlat et al. [23], BBC - Banabic et al. [24]), plus two hardening laws (isotropic and kinematic AutoForm model [25]) and their combinations. The parameters of kinematic hardening were proposed by the AutoForm software material generator. The simulation results using the FEM are presented in the next section and compared with experimental values.

In the real forming process several design and process parameters vary during production. Material properties and thickness vary from coil to coil and even within the same blank (tolerances). Also parameters such as blank position, blankholder forces, friction, and several others do vary within a certain range (noise). Often this "natural" variation leads to varying results in terms of part quality (e.g. formability or springback issues) during the manufacturing process. These unstable production conditions can finally cause unexpected part rejection.

Standard FEM tools limited to individual (single) simulations cannot take this "natural" variation into account as the simulation set-up of the design and process parameters consists of specific values instead of variations. Hence the result for an individual FEM simulation can differ significantly from reality in those cases of unstable production conditions [26]. However at this stage it is assumed that single simulation is sufficiently representative for the forming process.

The criterion of correlation coefficient was used in order to evaluate correspond the numerical models to reality. Correlation coefficient $C_{C}(9)$ measures the statistical correlation between the predicted values $p$ and the actual values $a$. It is defined by three parameters. $S_{P A}$ (10) is the average value of the products for the each analysed point deviation - differences between the predicted and actual values. $S_{P}(11)$ and $S_{A}(12)$ are the mean-squared errors of 
the predicted and actual values. The correlation coefficient $C_{C}$ ranges from 1 for perfectly correlated results, through to 0 when there is no correlation, to -1 when the results are perfectly correlated negatively. Of course, negative values should not occur for reasonable prediction methods [21]. The correlation coefficient is defined as:

$$
\begin{gathered}
C_{C}=\frac{S_{P A}}{\sqrt{S_{P} S_{A}}} \\
S_{P A}=\frac{\sum_{i}\left(p_{i}-\bar{p}\right)\left(a_{i}-\bar{a}\right)}{n-1} \\
S_{P}=\frac{\sum_{i}\left(p_{i}-\bar{p}\right)^{2}}{n-1} \\
S_{A}=\frac{\sum_{i}\left(a_{i}-\bar{a}\right)^{2}}{n-1}
\end{gathered}
$$

The correlation between the FEM and the experiment was tested in two ways: common correlation of the whole part (evaluated at 216 measured points) (Fig. 7 left) and twist correlation in three sections. It has already been stated that analysing a whole section's profile takes into account all three types of springback: angular change, sidewall curl, and twist. Twist is mostly expressed at the drawing part's bottom and for this reason only this sectional area was used for our calculation (Fig. 7 right). This approximation was assumed to be enough representation for twist springback evaluation.

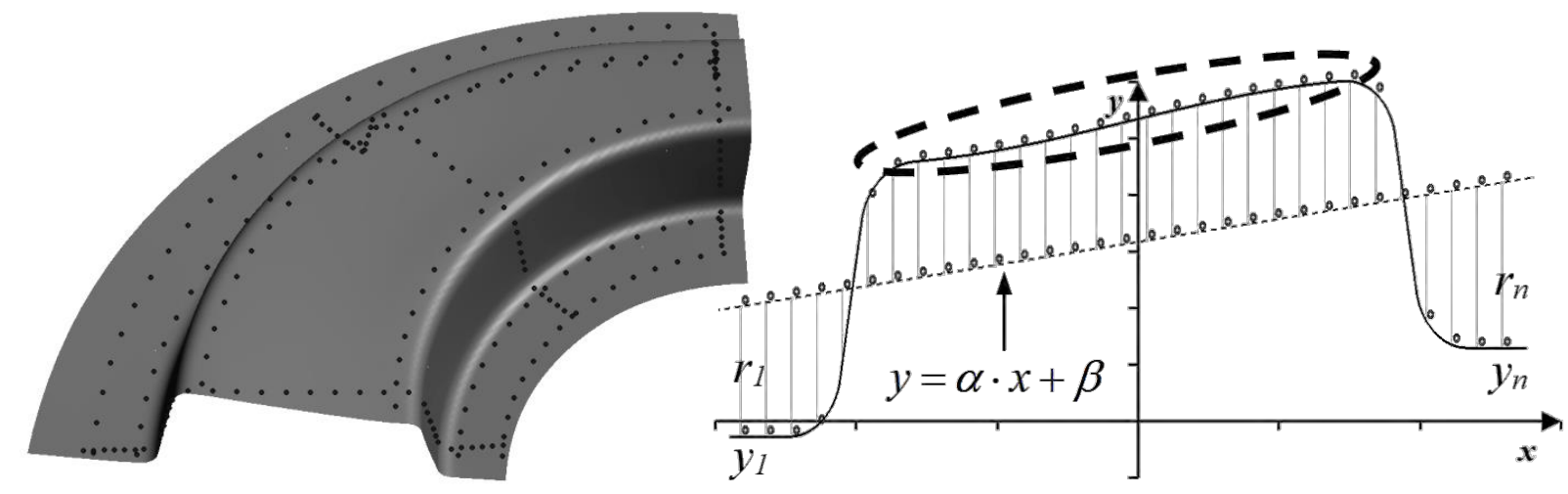

Figure 7: Points for common correlation analysis (left) and the selection of profile points for twist springback evaluation (right).

\section{RESULTS AND DISCUSSION}

Twist values of section profiles regarding the drawing parts' bottoms for different blank rolling directions are presented below. FEM and experimental results for previously defined sections are represented in the same diagrams to enable clear comparison.

In section 1 FEM the springback results were overestimated (Fig. 8) compared to the experimental results. Consequently twist springback predictions for all combinations of FEM material models provided higher absolute values. The effect of blank rolling direction on twist springback was visible, although its deviation was within a narrow framework: $0.27^{\circ}$ for different FEM models and $0.36^{\circ}$ for the experimental.

In section 2 there is opposite situation compared to previous section (Fig. 9). Twist prediction of FEM is underestimated; it is supposed the reason is in wrinkling tendency in this area of the product and its uncontrolled influence on final geometry. 


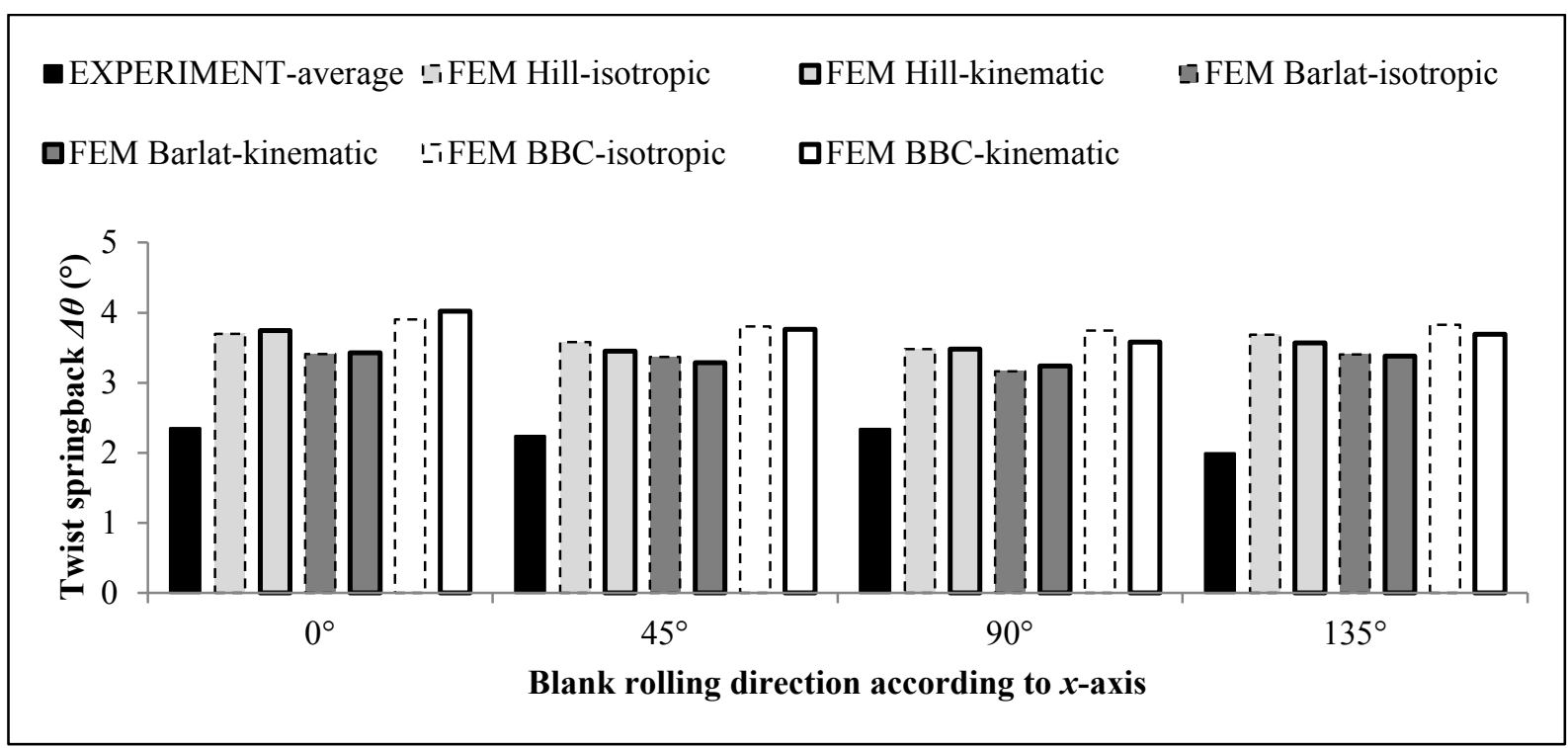

Figure 8: FEM and experimental values of twist springback depending on the blank rolling direction for section 1.

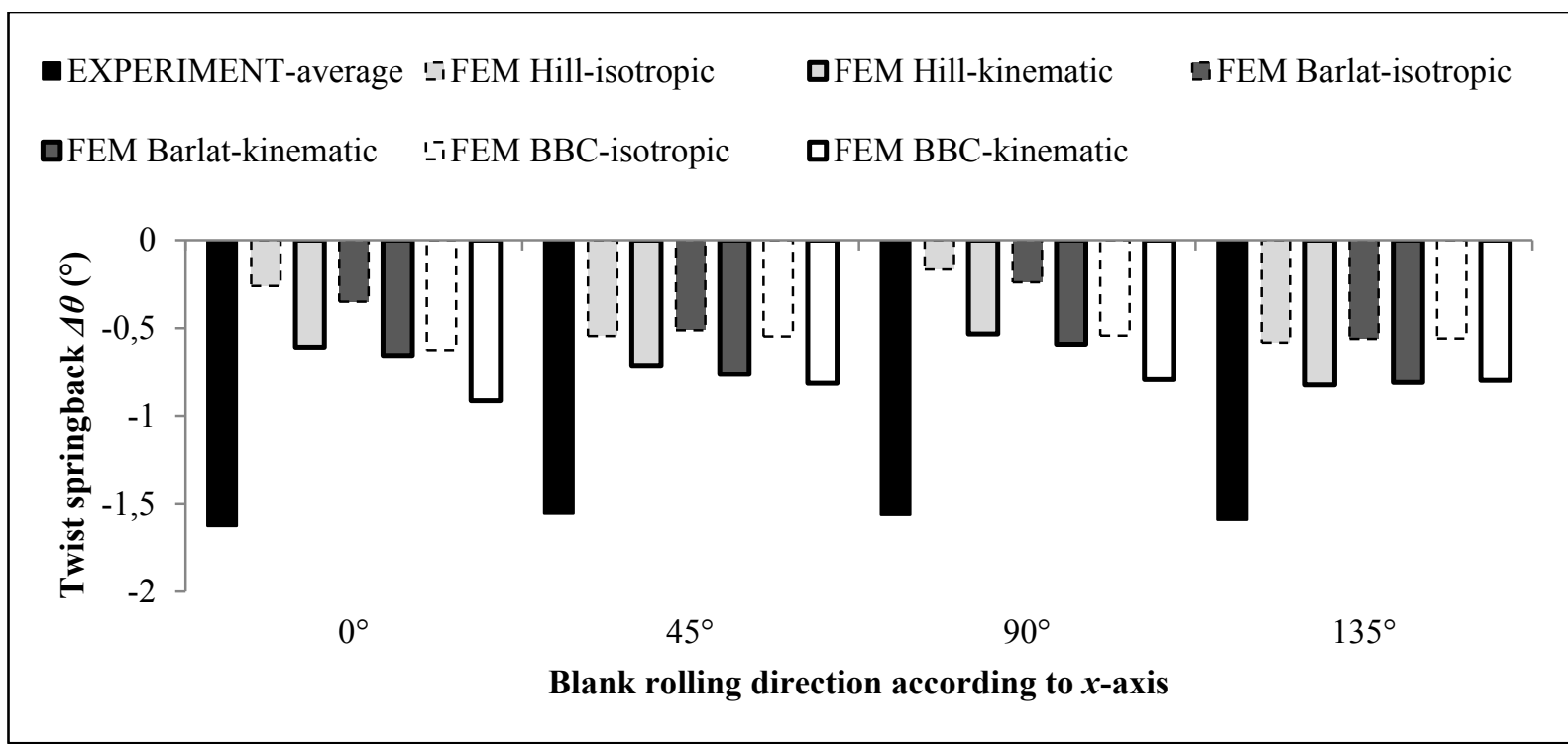

Figure 9: FEM and experimental values of twist springback depending on the blank rolling direction for section 2 .

The lowest correlation between FEM and experiment was reached in section 3, where FEM predicted twisting even in the opposite direction (Fig. 10). The potential reason for the differences between the predicted and real twist behaviour was an insufficiently accurate simulation set-up because of the number of questionable predicted parameter values starting with the material models, the numerical parameters of simulation and even unexpected deformations of experimental device elements (for instance the blank holder). The sheet material's properties were in our case only derived at from uniaxial tensile tests and, for the kinematic hardening law only by using the software suggested (not physically tested) parameter values. Both facts can have significant impact on the accuracy of the springback prediction.

After comparing the twist (Fig. 11) and common part correlation (Fig. 12) of the FEM models according to the real experiments, it was possible to conclude that kinematic 
hardening laws enabled more accurate springback predictions for all three yielding criteria tested during this work. In general it was also possible to confirm that the BBC yield criterion allows more sufficient springback predictions compared to the Barlat and traditional Hill models.

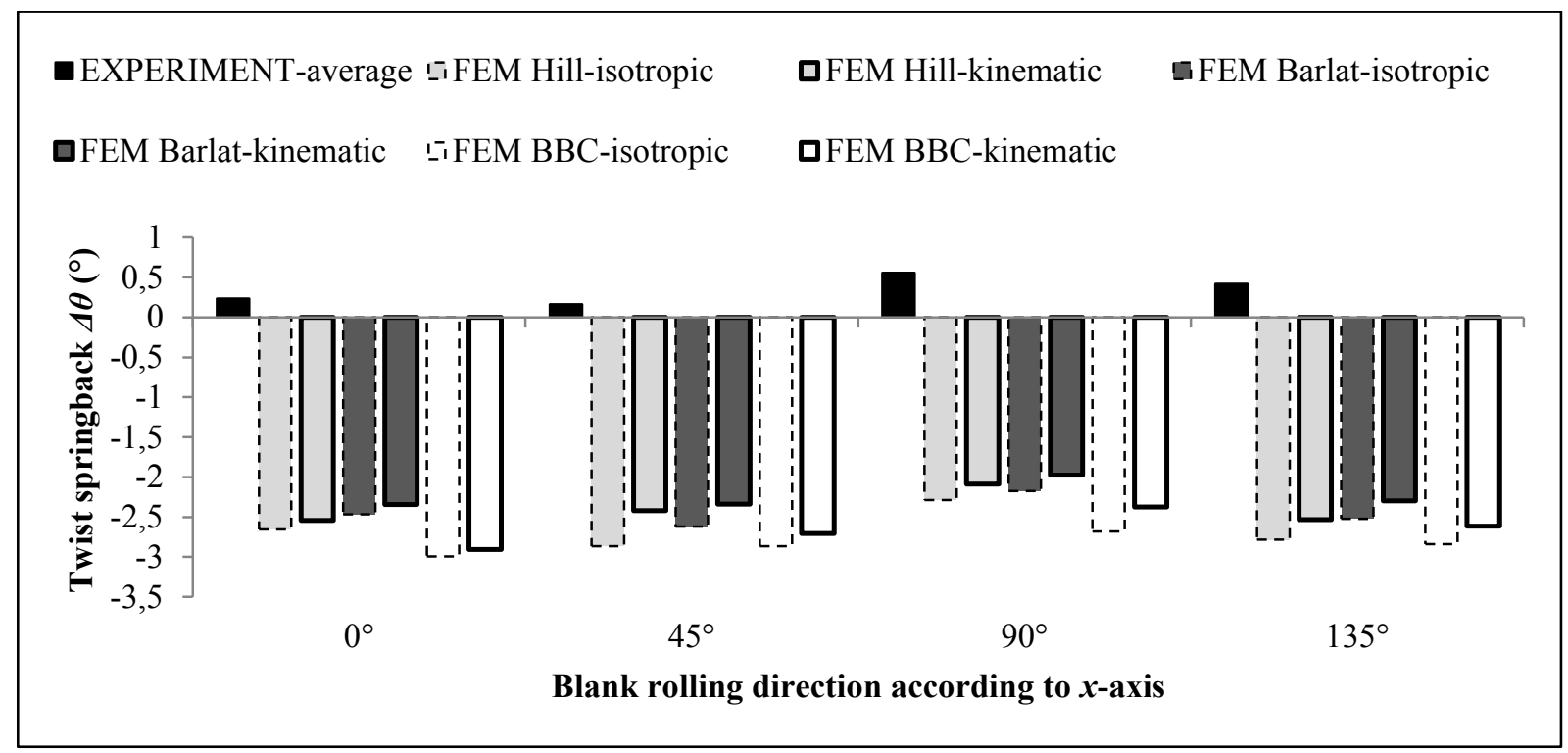

Figure 10: FEM and experimental values of twist springback depending on the blank rolling direction for section 3 .

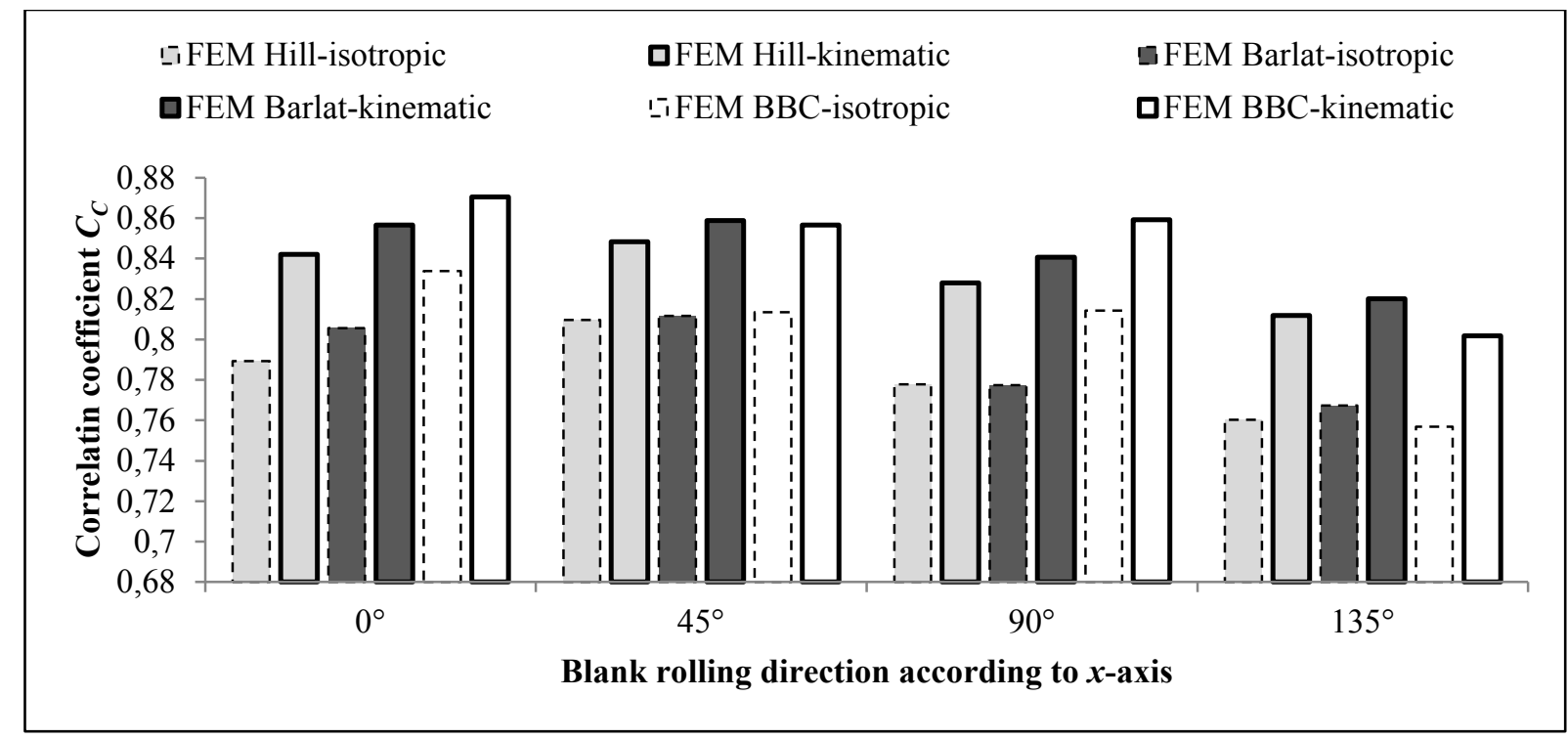

Figure 11: Correlation coefficient of twist springback prediction.

If the final testing part contours' data of FEM prediction and experiments are compared (Fig. 13) obviously the material draw-in is insufficiently robust. This can lead to a different twisting moment and subsequently different twisting springback. Differences in material draw-in can be caused by several differences in process conditions. Potential influence parameters - variation of initial position of the blank, binder model approach, friction conditions - are sources for further investigations of twist springback in order to better reflect measured data after experiments. However we can confirm that all of the FEM draw-in 
predictions regarding kinematic hardening were closer to reality compared to the isotropic hardening laws.

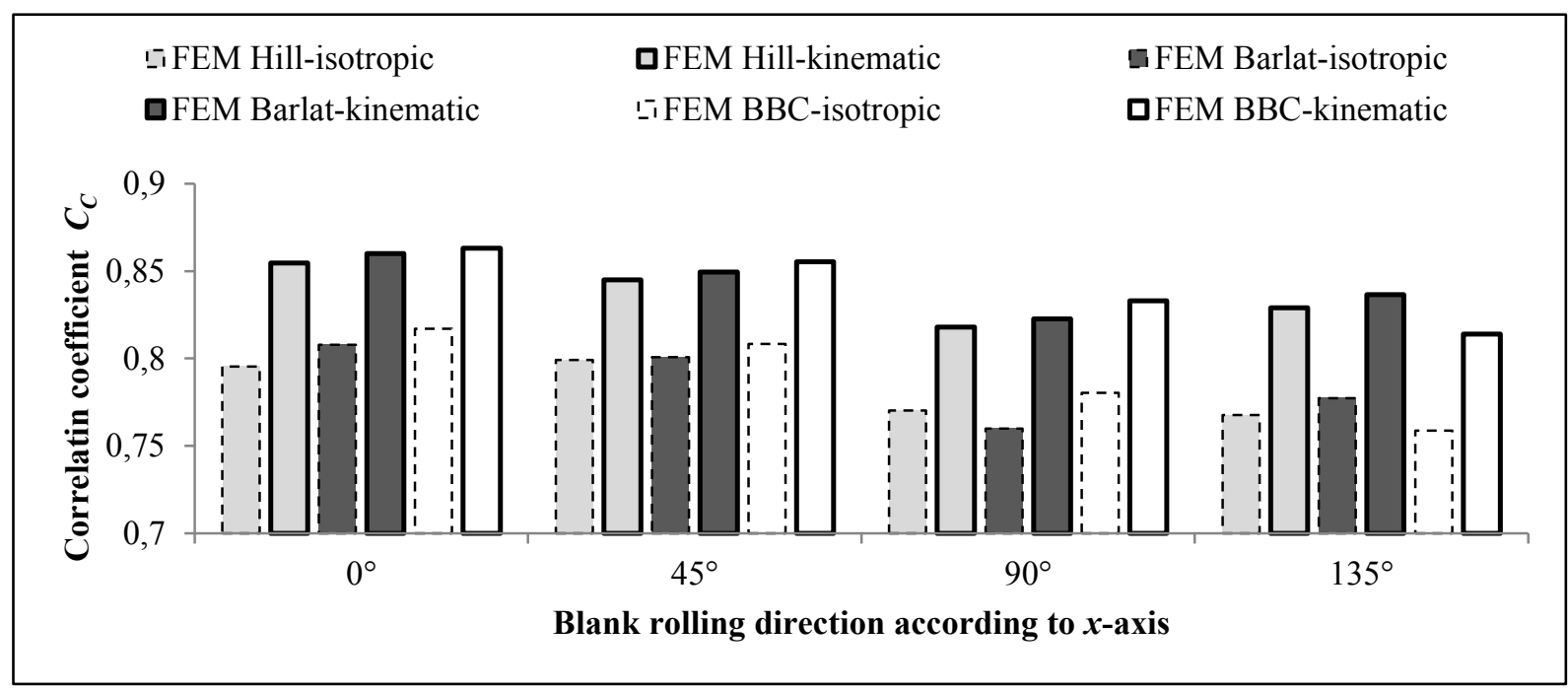

Figure 12: Correlation coefficient of different material models' combinations, evaluated in 216 measured points.

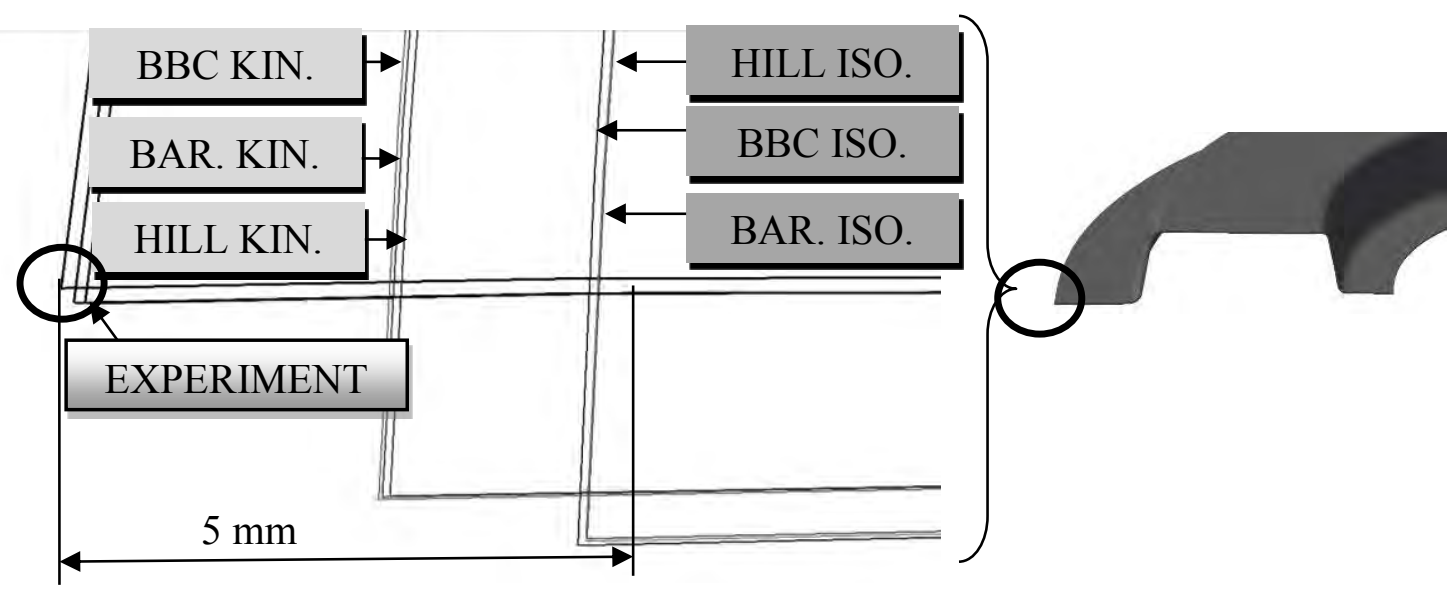

Figure 13: Variation of draw-in for different material models and three experimental results (rolling direction $0^{\circ}$ according to $x$ - axis).

\section{CONCLUSION}

Springback is of great concern throughout the sheet metal-forming industry today. There are different types of springback and twist springback is one of the more complex examples of it. This paper proposed a new twist springback definition and demonstrated it on a referenced sheet metal part. FEM simulation and real experiments were performed to investigate the twist springback and its predictability, using several material models. The effect of the blank rolling direction on the twist springback was also analysed. The following conclusions were reached regarding the twist springback phenomenon and its prediction:

- Accurate twist springback prediction is quite exacting. It is also well-known that for other basic springback types (angular change and sidewall curl) special modelling techniques are needed for accurate prediction (i.e. Bauschinger effect consideration, ...) and for twist springback this need even increases. Another difficulty is that twist springback is measured 
indirectly through section profile analyses and this can also cause some deviation in the twist's absolute value. However, in principle it should be possible with the help of contemporary FEM AutoForm software to predict twist springback correctly, if the process set-up in the simulation is similar to reality.

- FEM simulations of the springback phenomenon after the sheet metal-forming process using common material models (isotropic hardening, Hill's yielding behaviour) are less accurate compared to the advanced material models Barlat and BBC. This was well expressed regarding the comparison between FEM and the experimental results of the referenced part twist springback in this paper. Kinematic hardening laws enable more correlated FEM results. There is a cost-benefit conflict in industrial cases because with advanced (costly) material models better springback prediction is possible.

- Using different material models causes variation in the FEM predicted draw-in. The problem of draw-in variation could also be noted in the experimental results.

- Blank rolling direction has some influence on the twist springback. This effect was also noted for our reference part. The effect of anisotropy and blank orientation cannot be neglected although their relationship to twist springback is hardly defined in a simple way.

During the forming tool design process it is our goal to minimise twist springback because its geometrical compensation is usually very extensive and a costly adaptation has to be performed of the forming tools. One of the bigger problems is the robustness of springback behaviour. Only for stable process without final part geometry variation can a sufficient compensation procedure be performed using the FEM approach. Thus in the springback prediction of complex sheet metal parts it is necessary to take into account the stochastic nature of the material and the varying technological parameters' values.

\section{ACKNOWLEDGEMENTS}

This operation was partly financed by the European Union, European Social Fund.

\section{REFERENCES}

[1] Wagoner, R. H.; Wang, J. F.; Li, M. (2006). Springback, Semiatin, S. L. (Ed.), ASM Handbook, Volume 14B, Metalworking: Sheet Forming, ASM International, Ohio, 733-755

[2] Marciniak, Z.; Duncan, J. L.; Hu, S. J. (2002). Mechanics of Sheet Metal Forming, ButterworthHeinemann, Oxford

[3] WorldAutoSteel. Advanced High Strength Steel (AHSS) Application Guidelines, Version 4.1, from http://www.worldautosteel.org/, accessed on 16-8-2013

[4] Mole, N.; Cafuta, G.; Stok, B. (2013). A method for optimal blank shape determination in sheet metal forming based on numerical simulations, Strojniski vestnik - Journal of Mechanical Engineering, Vol. 59, No. 4, 237-250, doi:10.5545/sv-jme.2012.989

[5] Li, K. P.; Carden, W. P.; Wagoner, R. H. (2002). Simulation of springback, International Journal of Mechanical Sciences, Vol. 44, No. 1, 103-122, doi:10.1016/s0020-7403(01)00083-2

[6] Xu, W. L.; Ma, C. H.; Li, C. H.; Feng, W. J. (2004). Sensitive factors in springback simulation for sheet metal forming, Journal of Materials Processing Technology, Vol. 151, No. 1-3, $217-$ 222, doi:10.1016/j.jmatprotec.2004.04.044

[7] Panthi, S. K.; Ramakrishnan, N.; Pathak, K. K.; Chouhan, J. S. (2007). An analysis of springback in sheet metal bending using finite element method (FEM), Journal of Materials Processing Technology, Vol. 186, No. 1-3, 120-124, doi:10.1016/j.jmatprotec.2006.12.026

[8] Livatyali, H.; Wu, H. C.; Altan, T. (2002). Prediction and elimination of springback in straight flanging using computer-aided design methods: Part 2: FEM predictions and tool design, Journal of Materials Processing Technology, Vol. 120, No. 1-3, 348-354, doi:10.1016/s0924$\underline{0136(01) 01161-\mathrm{x}}$ 
[9] Meinders, T.; Burchitz, I. A.; Bonte, M. H. A.; Lingbeek, R. A (2008). Numerical product design: Springback prediction, compensation and optimization, International Journal of Machine Tools and Manufacture, Vol. 48, No. 5, 499-514, doi:10.1016/j.ijmachtools.2007.08.006

[10] Volk, M.; Nardin, B.; Dolsak, B. (2011). Application of numerical simulations in the deepdrawing process and the holding system with segments' inserts, Strojniski vestnik - Journal of Mechanical Engineering, Vol. 57, No. 9, 697-703, doi:10.5545/sv-jme.2010.258

[11] Stefic, T.; Juric, A.; Marovic, P. (2012). Experimental analysis of combined action of bending, shear and torsion on timber beams, Technical Gazette, Vol. 19, No. 3, 653-658

[12] Dezelak, M.; Pahole, I.; Ficko, M.; Brezocnik, M. (2012). Machine learning for the improvement of springback modelling, Advances in Production Engineering \& Management, Vol. 7, No. 1, $17-$ 26

[13] Hudovernik, M.; Staupendahl, D.; Gharbi, M.; Hermes, M.; Tekkaya, A. E.; Kuzman, K.; Slabe, J. M. (2013). 3D numerical analysis of 2D profile bending with the torque superposed spatial bending method, Strojniski vestnik - Journal of Mechanical Engineering, Vol. 59, No. 3, 139147, doi:10.5545/sv-jme.2012.483

[14] Pavazza, R.; Matokovic, A.; Plazibat, B. (2013). Bending of thin-walled beams of symmetrical open cross-sections with influence of shear, Transactions of FAMENA, Vol. 37, No. 3, 17-30

[15] Roll, K. (2008). Simulation of sheet metal forming - necessary developments in the future, Proceedings of the $7^{\text {th }}$ International Conference and Workshop on Numerical Simulation of $3 D$ Sheet Metal Forming Processes, Interlaken, 3-12

[16] Li, H.; Sun, G.; Li, G.; Gong, Z.; Liu, D.; Li, Q. (2011). On twist springback in advanced highstrength steels, Materials \& Design, Vol. 32, No. 6, 3272-3279, doi:10.1016/j.matdes.2011.02.035

[17] Takamura, M.; Sakata, M.; Fukui, A.; Hama, T.; Miyoshi, Y.; Sunaga, H.; Makinouchi, A.; Asakawa, M. (2010). Investigation of twist in curved hat channel products by elastic-plastic finite element analysis, International Journal of Material Forming, Vol. 3, No. 1 Supplement, 131-134, doi:10.1007/s12289-010-0724-1

[18] Takamura, M.; Fukui, A.; Yano, H.; Hama, T.; Sunaga, H.; Makinouchi, A.; Asakawa, M. (2011). Investigation on twisting and side wall opening occurring in curved hat channel products made of high strength steel sheets, AIP Proceedings - Proceedings of the $8^{\text {th }}$ International Conference and Workshop on Numerical Simulation of 3D Sheet Metal Forming Processes, Seoul, 887-894, doi:10.1063/1.3623699

[19] Ishiwatari, A.; Kano, H.; Hiramoto, J.; Inazumi, T. (2012). Improvement on CAE model for accurate torsional springback prediction in high strength steel part forming, Key Engineering Materials, Vol. 504-506, 437-442, doi:10.4028/www.scientific.net/KEM.504-506.437

[20] AutoForm Engineering GmbH (2012). AutoForm Software Manual R3.1, Zurich

[21] Witten, I. H.; Frank, E.; Hall, M. A. (2011). Data Mining: Practical Machine Learning Tools and Techniques (Third Edition), Morgan Kaufmann / Elsevier, Burlington

[22] Hill, R. (1993). A user-friendly theory of orthotropic plasticity in sheet metals, International Journal of Mechanical Sciences, Vol. 35, No. 1, 19-25, doi:10.1016/0020-7403(93)90061-X

[23] Barlat, F.; Becker, R. C.; Hayashida, Y.; Maeda, Y.; Yanagawa, M.; Chung, K.; Brem, J. C.; Lege, D. J.; Matsui, K.; Murtha, S. J.; Hattori, S. (1997). Yielding description for solution strengthened aluminum alloys, International Journal of Plasticity, Vol. 13, No. 4, 385-401, doi:10.1016/S0749-6419(97)80005-8

[24] Banabic, D.; Kuwabara, T.; Balan, T.; Comsa, D. S. (2004). An anisotropic yield criterion for sheet metals, Journal of Materials Processing Technology, Vol. 157-158, 462-465, doi:10.1016/ j.jmatprotec.2004.07.106

[25] Kubli, W.; Krasovskyy, A.; Sester, M. (2008). Advanced modeling of reverse loading effects for sheet metal forming processes, Proceedings of the $7^{\text {th }}$ International Conference and Workshop on Numerical Simulation of 3D Sheet Metal Forming Processes, Interlaken, 479-484

[26] Edwin Raja Dhas, J.; Kumanan, S. (2013). Modeling and prediction of HAZ using finite element and neural network modeling, Advances in Production Engineering \& Management, Vol. 8, No. 1, 13-24, doi:10.14743/apem2013.1.149 